\title{
A Comparison of Implants Used in Double Door Laminoplasty : Allogeneic Bone Spacer versus Hydroxyapatite Spacer
}

\author{
Dong Yoon Lee, M.D., Chang Kyu Lee, M.D., In-Soo Kim, M.D., Ph.D. \\ Department of Neurosurgery, Keimyung University, School of Medicine, Dongsan Medical Center, Daegu, Korea
}

\begin{abstract}
Objective : The aim of this study was to compare the clinical and radiological outcomes associated with the use of hydroxyapatite (HA) spacer and allogeneic bone (AB) spacer in laminoplasty.

Methods : From January 2006 to July 2014, 79 patients with cervical spondylotic myelopathy or ossification of the posterior longitudinal ligament underwent cervical laminoplasty. The radiologic parameters were obtained from plain radiography and three-dimensional computed tomography. All images were taken before and after surgery. Cervical lordosis, spinal canal dimension, fusion between lamina and spacer, and resorption of spacer were checked. Clinical outcomes were assessed using visual analog scale and Japanese Orthopedic Association.

Results : Double-door laminoplasty was performed on 280 levels : 182 in the HA group and 98 in the AB group. The mean follow-up was 23.1 months (range : 4-69 months). Similar fusion rates were found in these groups ( $p=0.3)$. The resorption rate between lamina and spacer was lower in the HA group $(p<0.001)$. During the immediate postoperative period, the canal dimension of both groups increased compared with the results in the preoperative period. However, the canal dimension of the AB group decreased over time compared with that of the HA group ( $p<0.001)$.

Conclusion : Double-door laminoplasty improved the clinical outcomes of both groups. However, the spinal canal dimension in the $A B$ group showed a greater degree of reduction than in the HA group at the final postoperative follow-up. Therefore, we suggest that surgeons consider the use of larger-sized AB spacers in double-door laminoplasties.
\end{abstract}

Key Words : Allograft · Hydroxyapatites · Cervical myelopathy · Ossification of posterior longitudinal ligament · Spinal fusion.

\section{INTRODUCTION}

Cervical laminoplasty was introduced in the early 1980 s as a successful means of addressing multilevel cervical spinal stenosis secondary to either cervical spondylotic myelopathy (CSM) or ossification of posterior longitudinal ligament (OPLL) ${ }^{23)}$. The goal of laminoplasty is to indirectly decompress the spinal canal by opening one or both sides of the lamina. In this procedure, the "open-door" technique, which was popularized by Hirabayashi et al. ${ }^{2)}$ can be used. Later on, other adaptations of this surgical technique including the double-door approach where the spinous process is split open were developed. Although both techniques are effective in improving neurologic outcomes, doubledoor laminoplasty is better than open-door laminoplasty when it comes to clinical outcomes such as axial neck pain, perioperative complication, and anatomical alignment ${ }^{13,15,18)}$. Double- door laminoplasty has been considered as an effective and safe method for decompressing the multi-segmental cervical lesions caused by CSM, OPLL, or intervertebral disc herniation with developmental canal stenosis, as well as for achieving the immediate stability of these lesions ${ }^{1,3,8,9,14,19)}$. For spinal canal decompression and stability of the spine, various materials were used in this procedure, which include : autologous grafts, hydroxyapatite (HA) spacers, and allogeneic bone $(\mathrm{AB})$ spacers. However, the pros and cons of individual implants have not been thoroughly investigated. In addition, many studies have compared heterogeneous groups or small individual case series, but there is still a lack in direct comparisons among these options. In this study, we compared double-door laminoplasty using HA spacers (Apacerum ${ }^{\circledR}$; Asahi Optical Co., Ltd., Tokyo, Japan) and AB spacers (Allo-Spine ${ }^{\circledR}$; CG Bio, Seoul, Korea) to analyze the clinical and radiological outcomes in patients.

- Received : May 25, 2016 • Revised : June 2, 2016 • Accepted : September 22, 2016

- Address for reprints : In-Soo Kim, M.D., Ph.D.

Department of Neurosurgery, Keimyung University, School of Medicine, Dongsan Medical Center, 56 Dalseong-ro, Jung-gu, Daegu 41931, Korea

Tel : +82-53-250-7730, Fax : +82-53-250-7356, E-mail : neurokim@dsmc.or.kr

- This is an Open Access article distributed under the terms of the Creative Commons Attribution Non-Commercial License (http://creativecommons.org/licenses/by-nc/3.0) which permits unrestricted non-commercial use, distribution, and reproduction in any medium, provided the original work is properly cited. 


\section{MATERIALS AND METHODS}

\section{Patient selection}

We retrospectively identified 79 patients ( 59 men, 20 women) with CSM or OPLL who underwent double-door laminoplasty between January 2006 and July 2014. These patients were divided into two groups : laminoplasty using HA spacer (HA group) and $\mathrm{AB}$ spacer ( $\mathrm{AB}$ group). Patients with cervical kyphosis, evidence of cervical instability, serious medical problems, as well as those who underwent prior anterior cervical surgery were excluded. Patient characteristics including gender, age, bone mineral density, alcohol, and smoking histories were obtained (Table 1).

\section{Radiological evaluation}

Plain radiography and three-dimensional computed tomography (3-D CT) were performed pre- and postoperatively. Plain radiography was performed in all 79 patients during the follow- up period. However, only 39 of them underwent CT during the follow-up due to death and personal reasons such as financial concerns. Those who were followed up only underwent plain radiography. Cervical lordosis, spinal canal dimension, fusion between lamina and spacer, and resorption of spacer were examined. Cervical lordosis was defined as the angle between C2 and C7 inferior endplates. Change in overall cervical lordosis was assessed using the radiographic images (Fig. 1). The transverse area of the cervical canal was measured at the level of the vertebral pedicles using a computer software (Marosis, M-View Ver. 5.4). As visualized on CT images, bone fusion of the spacer was determined as the disappearance of the gap at the interface between the grafted spacer and host bone with new bone formation. On the other hand, spacer resorption was defined as the change in the size and shape of the spacer on CT images (Fig. 2).

\section{Surgical procedure}

All laminoplasties were performed by a single surgeon (Dr.

Table 1. Characteristic of the two patient groups

\begin{tabular}{|c|c|c|c|}
\hline Characteristic & HA group $(n=51)$ & AB group $(n=28)$ & $p$ value \\
\hline Mean age, years (range) & $63.1(37-87)$ & $62.8(42-83)$ & 0.931 \\
\hline Mean follow up duration, months (range, months) & $33.75(4-69)$ & $17.1(7-35)$ & \\
\hline Sex (male : female) & $35: 16$ & $24: 4$ & 0.095 \\
\hline OPLL (\%) & $34(66.7)$ & $23(82.1)$ & 0.142 \\
\hline Osteoporosis (\%) & $22(43.1)$ & $13(46.4)$ & 0.778 \\
\hline Smoking (\%) & $18(35.3)$ & $11(39.3)$ & 0.725 \\
\hline Alcohol (\%) & $26(51.0)$ & $13(46.4)$ & 0.699 \\
\hline Surgical levels (total) & 182 & 98 & \\
\hline $\mathrm{C} 2$ & 2 & 2 & \\
\hline C3 & 40 & 24 & \\
\hline $\mathrm{C} 4$ & 48 & 28 & \\
\hline C5 & 50 & 26 & \\
\hline C6 & 40 & 18 & \\
\hline C7 & 2 & 0 & \\
\hline
\end{tabular}

Osteoporosis defined BMC <-2.5. HA : hydroxyapatite, $A B$ : allogeneic bone

Fig. 1. Cervical lordosis, defined as the angle between $\mathrm{C} 2$ and $\mathrm{C} 7$ inferior end plates. A : Pre-op. B : Immediately post op. C : Final follow up.
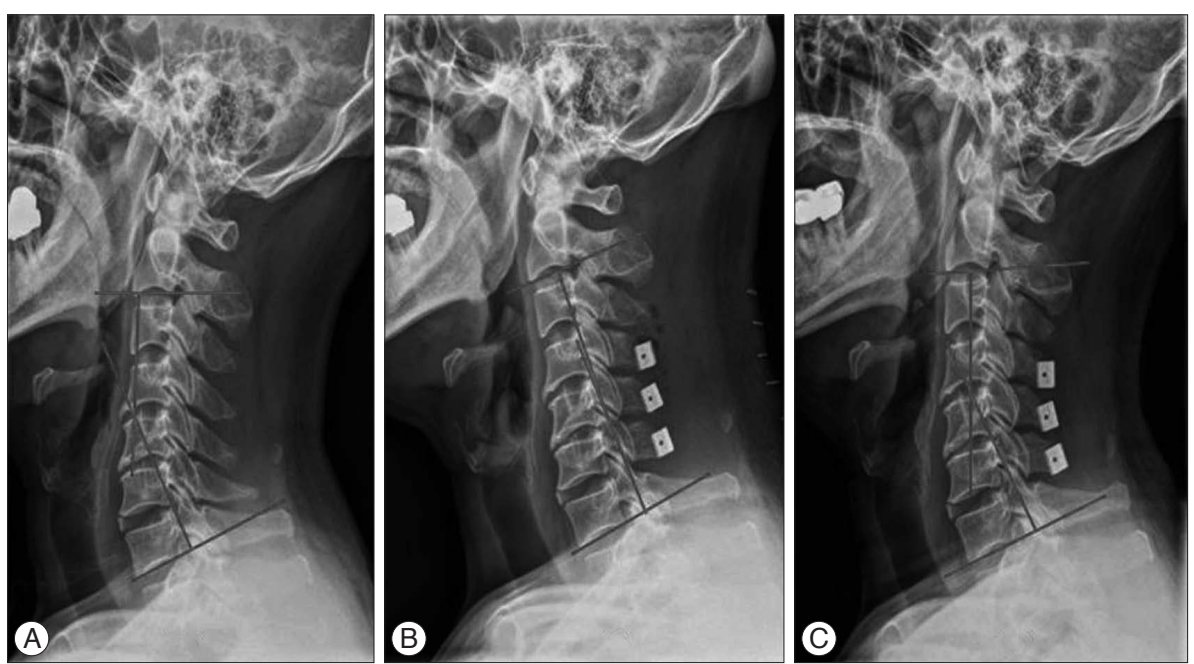

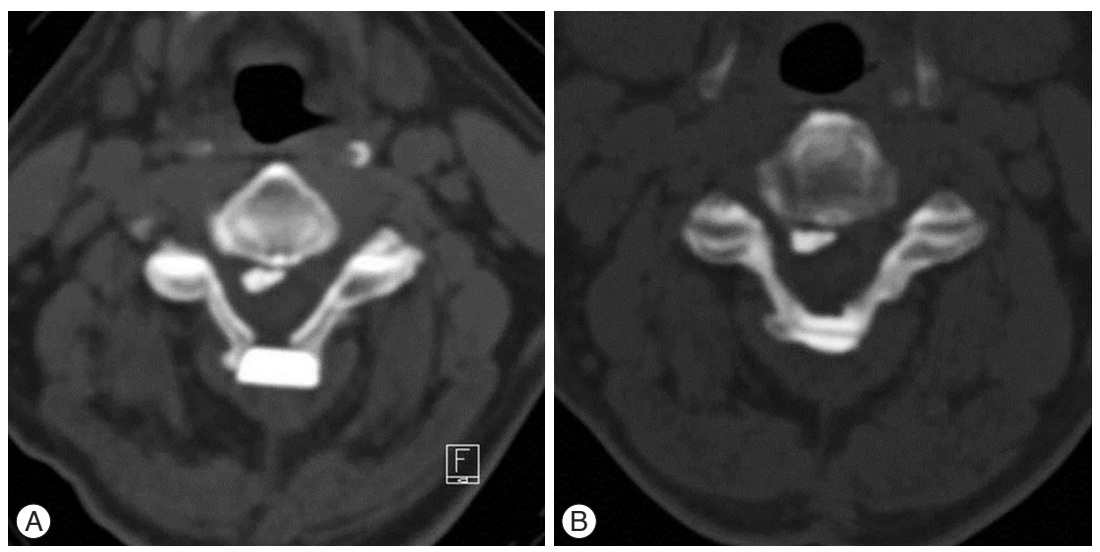

Fig. 2. Spacer resorption was defined that the shape of spacer is smaller or changed on CT images. A : Immediately post op. B : Final follow up.

Table 2. Cervical lordosis change

\begin{tabular}{ccccc}
\hline \multicolumn{1}{c}{ Groups } & $\begin{array}{c}\text { Pre-op } \\
\text { mean } \pm \text { SD (degrees) }\end{array}$ & $\begin{array}{c}\text { Immediately post OP } \\
\text { mean } \pm S D(\text { degrees })\end{array}$ & $\begin{array}{c}\text { Final follow up } \\
\text { mean } \pm S D(\text { degrees })\end{array}$ & $p$ value \\
\hline HA group $(\mathrm{n}=28)$ & $13.16 \pm 9.00$ & $11.61 \pm 8.04$ & $12.17 \pm 8.60$ & $0.131^{*}$ \\
AB group $(\mathrm{n}=11)$ & $16.93 \pm 9.07$ & $11.25 \pm 8.42$ & $11.13 \pm 7.08$ & \\
\hline
\end{tabular}

${ }^{*}$ Repeated measures ANOVA. HA : hydroxyapatite, $A B$ : allogeneic bone

Table 3. Spinal canal dimension change

\begin{tabular}{ccccc}
\hline \multicolumn{1}{c}{ Groups } & $\begin{array}{c}\text { Pre-op } \\
\text { mean } \pm \mathrm{SD}\left(\mathrm{mm}^{2}\right)\end{array}$ & $\begin{array}{c}\text { Immediately post OP } \\
\text { mean } \pm \operatorname{SD}\left(\mathrm{mm}^{2}\right)\end{array}$ & $\begin{array}{c}\text { Final follow up } \\
\text { mean } \pm \operatorname{SD}\left(\mathrm{mm}^{2}\right)\end{array}$ & $p$ value \\
\hline HA group $(\mathrm{n}=28)$ & $189.31 \pm 26.05$ & $275.25 \pm 34.21$ & $243.71 \pm 31.12$ & $<0.001^{\star}$ \\
AB group $(\mathrm{n}=11)$ & $185.48 \pm 32.62$ & $307.22 \pm 45.47$ & $254.50 \pm 54.70$ & \\
\hline
\end{tabular}

*Repeated measures ANOVA. HA : hydroxyapatite, AB : allogeneic bone

I.S. Kim). For surgical positioning, the Mayfield headrest was used wherein the neck was fixed from the neutral to the flexion position. After a vertical incision from the $\mathrm{C} 2$ to the $\mathrm{C} 7$ areas was made, the paravertebral muscle was carefully denuded. The researchers used double-door laminoplasty using an HA spacer or an $\mathrm{AB}$ spacer and the shallowest $1.7 \mathrm{~mm}$ Match Head Tool (Midas Rex ${ }^{\circledR}$ Legend EHS Stylus ${ }^{\circledR}$ High-Speed Surgical Drill; Medtronic, Inc., Fridley, MN, USA) to maximize the distance between split spinous processes and to enlarge the spinal canal area after applying a spacer between these areas. The outer cortex of the hinge site was minimally drilled to allow the reattachment of each site after splitting the spinous processes and to help with rapid bone fusion. Gentle care was taken while denuding the paravertebral muscle to minimize bleeding and pain after the operation. As much as possible, the researchers did not use electrocautery during dissection to prevent muscle atrophy at the follow-up period.

\section{Clinical evaluation}

Neurological status of the patient was preoperatively and postoperatively assessed using the Japanese Orthopedic Association (JOA) scores, while the pain intensity of the neck was assessed from $0-10$ using the neck visual analog scale (VAS; $0=$ no pain; $10=$ worst pain).

\section{Statistical analysis}

Parameters were analyzed using the Repeated Measures ANONA. The differences in the results were considered significant when $p$ values were $<0.05$. All results are expressed as mean \pm standard deviation. Analyses were performed using the IBM Statistical Package for the Social Sciences Version 18.0 (SPSS Inc., Chicago, IL, USA).

\section{RESULTS}

The mean follow-up duration was 23.1 months (range : 4-69 months). Of the 79 included patients, 22 were diagnosed with CSM and 57 with OPLL. Surgeries were performed on $280 \mathrm{lev}-$ els : 182 for the HA group and 98 for the AB group. Mean cervical lordosis changed from $13.54^{\circ} \pm 9.21^{\circ}$ to $12.16^{\circ} \pm 8.68^{\circ}$ in the HA group and from $16.93^{\circ} \pm 9.07^{\circ}$ to $11.13^{\circ} \pm 7.08^{\circ}$ in the $\mathrm{AB}$ group ( $p=0.131$ ) (Table 2 ). Immediately after the surgery, the spinal canal dimension increased from $189.31 \mathrm{~mm}^{2}$ to 275.25 $\mathrm{mm}^{2}$ in the HA group and from $185.48 \mathrm{~mm}^{2}$ to $307.22 \mathrm{~mm}^{2}$ in the $\mathrm{AB}$ group, but it decreased to $243.71 \mathrm{~mm}^{2}$ and $254.50 \mathrm{~mm}^{2}$, respectively, at the last follow-up ( $p<0.001$ ) (Table 3) (Fig. 3, 4). The dimension decreased during the last follow-up in both groups, but the degree of decrease in dimension was greater in the $\mathrm{AB}$ group than in the HA group. JOA scores changed from $12.35 \pm 4.67$ to $15.02 \pm 3.72$ in the HA group and from $13.04 \pm 4.19$ 
Fig. 3. The spinal canal dimension change in $\mathrm{HA}$ group. A : Immediately post op. B : Final follow up. HA : hydroxyapatite.
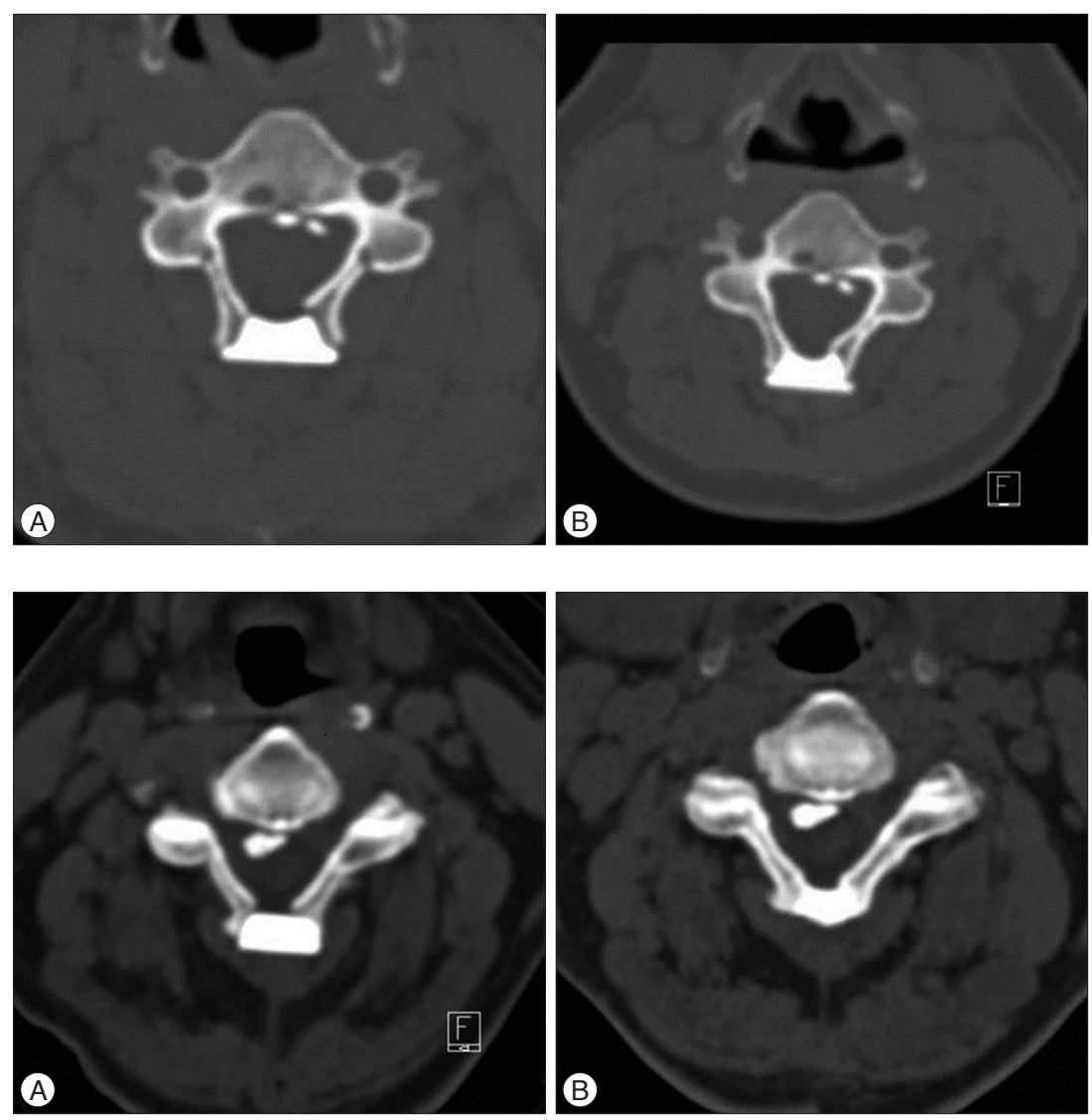

Fig. 4. The spinal canal dimension change in $A B$ group. A : Immediately post op. B : Final follow up. $A B$ : allogeneic bone.

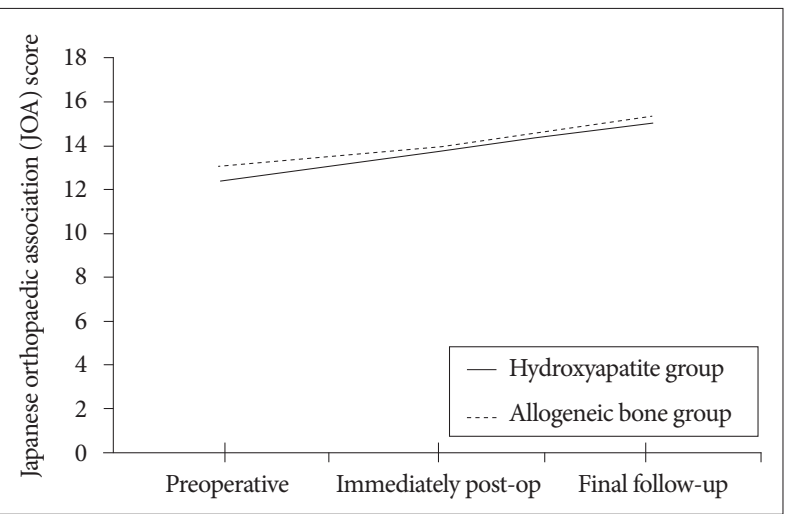

Fig. 5. Clinical outcome in JOA scores compared between preoperative, immediately post operative and final follow up.

to $15.29 \pm 3.13$ in the $\mathrm{AB}$ group ( $p=0.674$ ) (Fig. 5). Neck VAS scores changed from $4.65 \pm 3.10$ to $1.41 \pm 1.51$ in the HA group and from $4.54 \pm 1.71$ to $1.46 \pm 0.88$ in the $\mathrm{AB}$ group ( $p=0.598$ ) (Fig. 6). To compare both fusion and resorption rates, we chose the group with a similar follow-up term of 18 months. In the HA group, a total of 74 implants were used from which 55 achieved union. Meanwhile, in the $\mathrm{AB}$ group, a total of 37 implants were used from which 24 achieved union. However, there was no statistically significant difference found between the two groups $(p=0.3)$ (Table 4). In terms of resorption rate, a total of 74 spacers in the HA group were used from which resorption occurred in 6. On

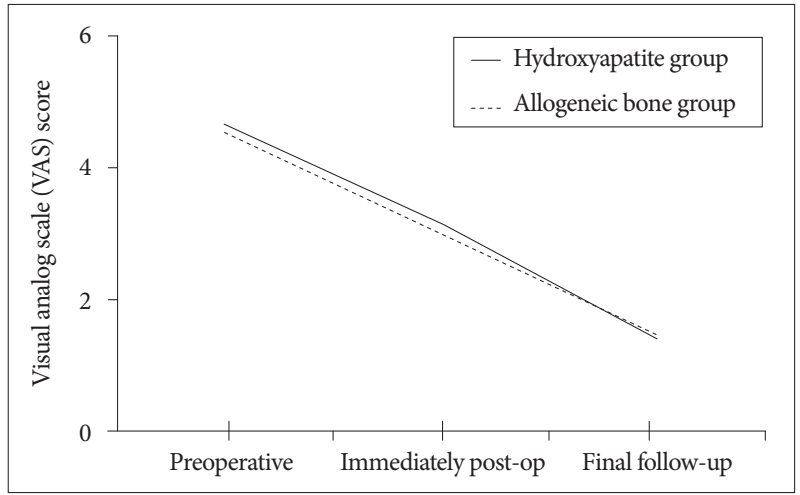

Fig. 6. Clinical outcome in VAS scores compared between preoperative, immediately post operative and final follow up.

the other hand, a total of 37 spacers in the $A B$ group were used from which resorption occurred in $19(p<0.001)$ (Table 5).

\section{DISCUSSION}

Numerous modifications and supplementary instruments were utilized to retain hinge patency and provide secure fixation in open-door or double-door laminoplasties, ${ }^{4,17)}$. Some examples of these are as follows : HA spacer, $\mathrm{AB}$ spacer, ceramic lamina, miniplate osteosynthesis, and autogenous bone grafting $^{4,24)}$. To be specific, AB spacer, HA spacer, autogenous bone graft, and ceramic block were used for the maintenance of an 
Table 4. Fusion between lamina and spacer

\begin{tabular}{lccc}
\hline \multicolumn{1}{c}{ Variable } & HA group, $\mathrm{n}(\%)$ & AB group, $\mathrm{n}(\%)$ & $p$ value \\
\hline Mean follow up duration, months (range, months) & $19.0(7-38)$ & $17.1(7-35)$ & $0.300^{*}$ \\
Union & $55(74.3)$ & $24(64.9)$ & $13(35.1)$ \\
Non-union & $19(25.7)$ & 37 & \\
Total & 74 & & \\
\hline
\end{tabular}

${ }^{*}$ chi-square test. $\mathrm{HA}$ : hydroxyapatite, $\mathrm{AB}$ : allogeneic bone

Table 5. Spacer resorption rate

\begin{tabular}{lccc}
\hline \multicolumn{1}{c}{ Variable } & HA group $(\%),(\mathrm{n}=74)$ & AB group $(\%),(\mathrm{n}=37)$ & $p$ value \\
\hline Mean follow up duration, months (range, months) & $19.0(7-38)$ & $17.1(7-35)$ & \\
Resorption $(\%)$ & $6(8.10)$ & $19(51.4)$ & $<0.001^{*}$ \\
\hline
\end{tabular}

${ }^{*}$ chi-square test. $\mathrm{HA}$ : hydroxyapatite, $\mathrm{AB}$ : allogeneic bone

opened lamina. Although these promote the bony healing of the grafted side and the maintenance of the laminar arch when spaces were used, these posed the risk of root or cord compression because of a graft kick-out ${ }^{4,5,22}$. In laminoplasty, HA and $\mathrm{AB}$ spacers have several benefits compared to the autologous bone graft. These include good biomechanical stability and reductions in operation time, blood loss, and donor site morbidi$\operatorname{ty}^{7,10-12,16)}$. It was reported that the fusion rates after the use of an HA spacer and $\mathrm{AB}$ spacer were $48.8 \%$ and $51 \%$, respectively ${ }^{16)}$. However, no study has actually directly compared these two groups. In this study, the fusion between the lamina and the spacer, as well as the resorption, was checked through the fine-section reconstruction of the CT. Since an HA spacer only has an osteoconduction activity compared with an $\mathrm{AB}$ spacer with both osteoconduction and osteoinduction activities, the fusion rate was expected to be higher in the $\mathrm{AB}$ group. In the current study, 55 of the 74 changes in the HA group and 24 of the 37 changes in the $\mathrm{AB}$ group were fused. While the result was not statistically significant, the HA group showed a similar fusion rate with $\mathrm{AB}$ group. Although the clinical outcomes improved in both groups, there were no statistically significant differences between them. This is because the shape and size of the spacers are similar, which allowed the canal dimension to increase in a similar proportion with the canal expansion postoperatively. In agreement with previous findings, this study observed the dimensional reduction of the spinal canal after an immediate postoperative widening ${ }^{7,16)}$. However, the degree of dimensional reduction was greater in the $\mathrm{AB}$ group on the final follow-up $\mathrm{CT}$ imaging. This may be taken into consideration in conjunction with the fusion rate. In addition, it may be related to the fusion of the newly formed bone, which narrowed the canal dimension. Moreover, spacer resorption may be important in this change in dimension. Originally, the spacer can widen the width of the canal by occupying the space between the spinous processes. However, with the increase in spacer resorption, its shape is changed, and the space between the spinous processes is narrowed. It is believed to result in a decrease because of its canalwidening effect. Aside from having been observed in many other studies, kyphotic deformities were also observed after laminoplasty in this study. However, additional follow-up is needed $^{3,6,18,20,21)}$

\section{Limitations of the study}

This study had several limitations. It was a retrospective analysis involving a relatively small number of patients. In particular, limited CT data were available because of the retrospective nature of this study. In addition, the fusion rates between the two groups were not accurately compared because the mean follow-up periods of each group was different. Thus, it is necessary to measure them again after sufficient follow-up periods. Prospective controlled studies using patient-based outcomes are required to compare outcomes and complications associated with these two implants. As supplements to this study, a broader scope and a longer follow-up duration are thus needed.

\section{CONCLUSION}

After double-door laminoplasty was performed with an $\mathrm{AB}$ spacer on one group and an HA spacer on another group, the clinical outcomes of both groups improved. In addition, similar fusion rates were found in these groups. However, the $\mathrm{AB}$ group had a greater degree of reduction in the spinal canal dimension than the HA group at the final postoperative follow-up. Therefore, we suggest that surgeons should consider the use of largersized $\mathrm{AB}$ spacers in double-door laminoplasties.

\section{References}

1. Chiba K, Ogawa Y, Ishii K, Takaishi H, Nakamura M, Maruiwa H, et al. : Long-term results of expansive open-door laminoplasty for cervical myelopathy--average 14-year follow-up study. Spine (Phila Pa 1976) 31 : 2998-3005, 2006

2. Hirabayashi K, Watanabe K, Wakano K, Suzuki N, Satomi K, Ishii Y : Expansive open-door laminoplasty for cervical spinal stenotic myelopathy. Spine (Phila Pa 1976) 8 : 693-699, 1983

3. Iwasaki M, Kawaguchi Y, Kimura T, Yonenobu K : Long-term results of expansive laminoplasty for ossification of the posterior longitudinal ligament of the cervical spine : more than 10 years follow up. J Neurosurg 96(2 Suppl) : 180-189, 2002

4. Jin SW, Kim SH, Kim BJ, Choi JI, Ha SK, Kim SD, et al. : Modified open- 
door laminoplasty using hydroxyapatite spacers and miniplates. Korean J Spine 11 : 188-194, 2014

5. Kanemura A, Doita M, Iguchi T, Kasahara K, Kurosaka M, Sumi M : Delayed dural laceration by hydroxyapatite spacer causing tetraparesis following double-door laminoplasty. J Neurosurg Spine 8 : 121-128, 2008

6. Kawaguchi Y, Kanamori M, Ishihara H, Ohmori K, Nakamura H, Kimura $\mathrm{T}$ : Minimum 10-year followup after en bloc cervical laminoplasty. Clin Orthop Relat Res (411) : 129-139, 2003

7. Kimura A, Seichi A, Inoue H, Hoshino Y : Long-term results of doubledoor laminoplasty using hydroxyapatite spacers in patients with compressive cervical myelopathy. Eur Spine J 20 : 1560-1566, 2011

8. Kimura I, Shingu H, Nasu Y : Long-term follow-up of cervical spondylotic myelopathy treated by canal-expansive laminoplasty. J Bone Joint Surg Br 77 : 956-961, 1995

9. Kong Q, Zhang L, Liu L, Li T, Gong Q, Zeng J, et al. : Effect of the decompressive extent on the magnitude of the spinal cord shift after expansive open-door laminoplasty. Spine (Phila Pa 1976) 36 : 1030-1036, 2011

10. Kubo S, Goel VK, Yang SJ, Tajima N : Biomechanical evaluation of cervical double-door laminoplasty using hydroxyapatite spacer. Spine (Phila Pa 1976) 28 : 227-234, 2003

11. Martin-Benlloch JA, Maruenda-Paulino JI, Barra-Pla A, Laguia-Garzaran M : Expansive laminoplasty as a method for managing cervical multilevel spondylotic myelopathy. Spine (Phila Pa 1976) 28 : 680-684, 2003

12. Nakano K, Harata S, Suetsuna F, Araki T, Itoh J : Spinous process-splitting laminoplasty using hydroxyapatite spinous process spacer. Spine (Phila Pa 1976) 17(3 Suppl) : S41-S43, 1992

13. Nakashima H, Kato F, Yukawa Y, Imagama S, Ito K, Machino M, et al. : Comparative effectiveness of open-door laminoplasty versus Frenchdoor laminoplasty in cervical compressive myelopathy. Spine (Phila Pa 1976) 39 : 642-647, 2014

14. Ogawa Y, Chiba K, Matsumoto M, Nakamura M, Takaishi H, Hirabayashi $\mathrm{H}$, et al. : Long-term results after expansive open-door laminoplasty for the segmental-type of ossification of the posterior longitudinal liga- ment of the cervical spine : a comparison with nonsegmental-type lesions. J Neurosurg Spine 3 : 198-204, 2005

15. Okada M, Minamide A, Endo T, Yoshida M, Kawakami M, Ando M, et al. : A prospective randomized study of clinical outcomes in patients with cervical compressive myelopathy treated with open-door or Frenchdoor laminoplasty. Spine (Phila Pa 1976) 34 : 1119-1126, 2009

16. Park JH, Jeon SR : Midline-splitting open door laminoplasty using hydroxyapatite spacers : comparison between two different shaped spacers. J Korean Neurosurg Soc 52 : 27-31, 2012

17. Patel CK, Cunningham BJ, Herkowitz HN : Techniques in cervical laminoplasty. Spine J 2 : 450-455, 2002

18. Ratliff JK, Cooper PR : Cervical laminoplasty : a critical review. J Neurosurg 98(3 Suppl) : 230-238, 2003

19. Sakaura H, Hosono N, Mukai Y, Ishii T, Iwasaki M, Yoshikawa H : Longterm outcome of laminoplasty for cervical myelopathy due to disc herniation : a comparative study of laminoplasty and anterior spinal fusion. Spine (Phila Pa 1976) $30: 756-759,2005$

20. Shimamura T, Kato S, Toba T, Yamazaki K, Ehara S : Sagittal splitting laminoplasty for spinal canal enlargement for ossification of the spinal ligaments (OPLL and OLF). Semin Musculoskelet Radiol 5 : 203-206, 2001

21. Suk KS, Kim KT, Lee JH, Lee SH, Lim YJ, Kim JS : Sagittal alignment of the cervical spine after the laminoplasty. Spine (Phila Pa 1976) 32 : E656E660, 2007

22. Tanaka N, Nakanishi K, Fujimoto Y, Sasaki H, Kamei N, Hamasaki T, et al. : Expansive laminoplasty for cervical myelopathy with interconnected porous calcium hydroxyapatite ceramic spacers : comparison with autogenous bone spacers. J Spinal Disord Tech 21 : 547-552, 2008

23. Tsuji $\mathrm{H}$ : Laminoplasty for patients with compressive myelopathy due to so-called spinal canal stenosis in cervical and thoracic regions. Spine (Phila Pa 1976) 7 : 28-34, 1982

24. Yang SC, Niu CC, Chen WJ, Wu CH, Yu SW : Open-door laminoplasty for multilevel cervical spondylotic myelopathy : good outcome in $12 \mathrm{pa}-$ tients using suture anchor fixation. Acta Orthop 79 : 62-66, 2008 